\title{
Mechanical deformation mechanism and verification of sections at junctions of light and dark tunnel in a mountain area
}

\author{
Jianbing Lv ${ }^{1}$, Yimin $W^{2}$, Xulong $\mathbf{L i}^{3}$, Fei Wang ${ }^{4}$, Zhengming Zou ${ }^{5}$, Yingmei Yin ${ }^{6}$ \\ 1, 2,3, ${ }^{6}$ School of Civil and Traffic Engineering, Guangdong University of Technology, \\ Guangzhou, 510006, China \\ ${ }^{4}$ Anhui Transport Consulting and Design Institute Co., Ltd, Anhui, China \\ ${ }^{5}$ Anhui Transportation Investment Group, Hefei City, Anhui, China \\ ${ }^{1}$ Corresponding author \\ E-mail: ${ }^{1}$ ljb@gdut.edu.cn, ${ }^{2} 542036363 @ q q . c o m,{ }^{3} 2215008477 @ q q . c o m,{ }^{4} 1249688680 @ q q . c o m$, \\ 51260669681@qq.com,6776725806@qq.com
}

Received 5 October 2018; received in revised form 11 December 2018; accepted 25 December 2018 DOI https://doi.org/10.21595/jve.2018.20285

Check for updates

Copyright $(2019$ Jianbing Lv, et al. This is an open access article distributed under the Creative Commons Attribution License, which permits unrestricted use, distribution, and reproduction in any medium, provided the original work is properly cited.

\begin{abstract}
Projects involving junctions of light and dark tunnel in mountainous areas are complex engineering problems that combine tunnel structure, slope rock-soil mass and protection projects. Such junctions suffer from a complex and changeable load. The stress and deformation of the junction varies under different conditions. Thus, it is a major source of inconvenience for construction and monitoring operations. In this paper, according to the load conditions at a junction of light and dark tunnel, we divide the junction hole into thrust, compression, and combined thrust-compression types. Three types of structures were simulated by numerical analysis, and we explored the structural deformation and stress of these types of tunnel under different condition. Thus, in any construction process, the mechanical deformation mechanism and the weak point in the structure should be worked out. Based on the weak parts, some monitoring points were installed, and four fields for monitoring were chosen. The monitoring results show that the actual deformation, stress and structural failure location are basically consistent with the numerical simulation results. The deformation mechanism of light and dark tunnel junction obtained can provide the basis for selecting the treatment measures and controlling the structural deformation. Furthermore, the results can also be used as a reference for similar engineering design, construction and site monitoring projects.
\end{abstract}

Keywords: mountain area, junction of light and dark tunnel, hole, mechanical deformation mechanism, site monitoring and verification.

\section{Introduction}

With the improvement in environmental awareness, environmental problems associated with highway construction have attracted increasing attention. One such problem is the slope near highway tunnels [1-3]. With the traditional method, we often need to anchor the slope when we excavate it, but that would destroy the vegetation near the portal, the surrounding environment and the landscape. Furthermore, it is possible to generate a high slope that may cause a geological disaster [4-6]. This effect will be especially significant when the tunnel is large, and the tunnel axis is parallel to the contour line. To reduce the adverse effect of tunnel construction, it is necessary to adopt some new tunnel construction technologies, such as a shed a half-hole that could reduce the brush slope [7-9]; and a front portal, which could prevent the destruction of vegetation [10]. The half-hole, which has received wide application, is suitable for different field conditions, including tunnel axes that are oblique or parallel to terrain contours [11].

Because of the complicated structure, changing load, and additional factors, the design and construction of a half tunnel portal section is very difficult: (1) The positions of the light and dark holes in the tunnel section are different. The size and distribution of the load structure are also 
different. (2) The buried depth is shallow, and the rock nearby is strongly weathered, which makes it extremely vulnerable to construction and rainfall. Thus, the physical and mechanical parameters of the rock are unstable. (3) The construction process for the junction of light and dark tunnels includes many procedures, which creates a complex force transmission process. Then, due to insufficient systematic research on this structure, a modest lack of attention to the project may lead to a large deformation and even cracks [12].

The strengthening of construction monitoring is an important means to ensure the safety of some special tunnel structures. Effective monitoring should be based on the correct analysis of the structure deformation characteristics. Therefore, it is necessary to study the deformation characteristics of the junction of light and dark tunnel. Then, we could provide a reference for the design, construction and monitoring of these junctions.

\section{Types of junctions of light and dark tunnel}

Many light and dark tunnel junctions appear because of the route constraint (i.e., the tunnel is in the position of the hill mouth, which cannot be crossed perpendicularly). Such a mountain is generally a small hill, and the rock nearby is mostly intensely-weathered rocks or slope residual soil layers (muddy or soil-like stone). For example, the Huangta highway (from Mount Huangshan to Taling and from Xiaohe to Taolin) has four three-lane tunnels with four light and dark tunnel junctions (Fig. 1). All of the junctions are in the mountain mouth (one near the residual layer, one in fully weathering phyllite, and two in fully weathered dacite). The rock nearby is thin and loose, so it is difficult to create an effective resistance to defense structure deformation. From the most unfavorable aspect, it is considered that the dark tunnel can only bear the loose soil's pressure, which has no significant resistance to the structure. Therefore, according to the shade junction on the tunnel's cross section, the light and dark tunnel junction can be divided into a number of types, including the thrust, compression, and combined thrust-compression types (Fig. 2). Then, we can easily analyze the different types of the structure's forces.

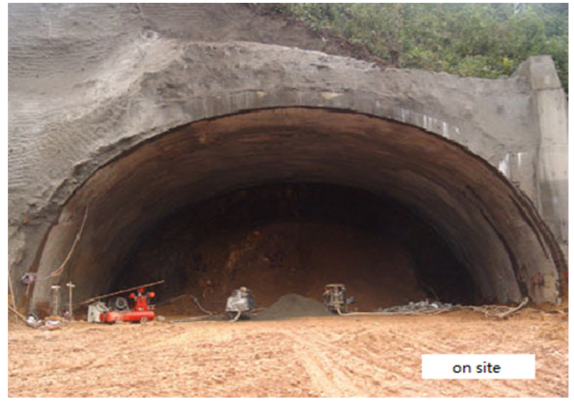

a) Huangshan Section in the

Changwuling tunnel, left line

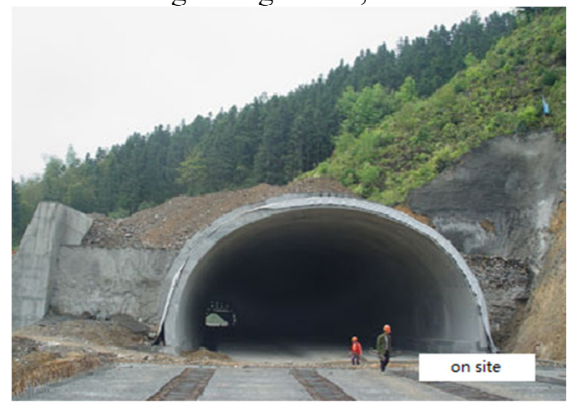

c) Zhuxia Section in the Huangshan tunnel, left line

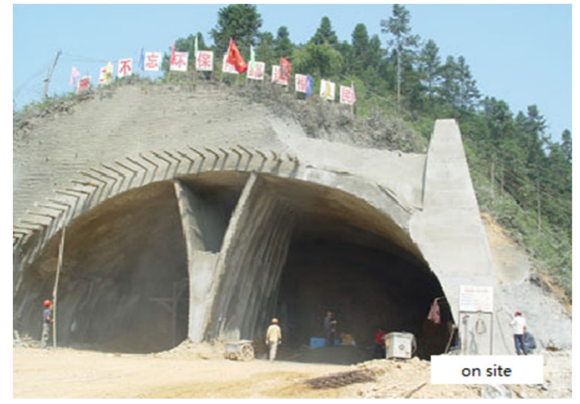

b) Taling Section in the Changwuling tunnel, right line

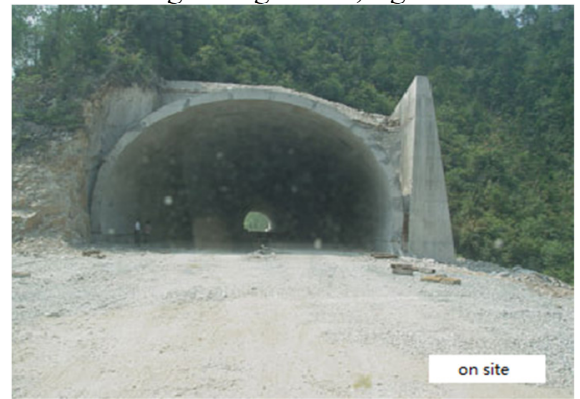

d) Zhuxia Section in the

Huangshan tunnel, right line

Fig. 1. Portals of half-buried tunnels 


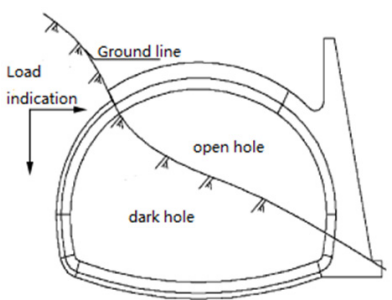

a) Thrust type

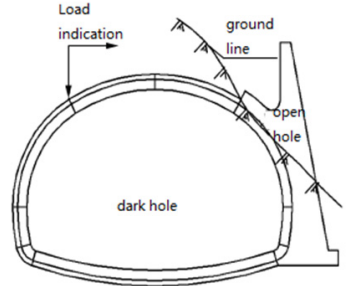

b) Compression type

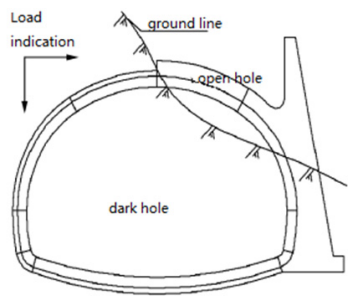

c) Combined thrust-compression type

Fig. 2. Types of portals of half-buried tunnels

(1) Thrust type light and dark tunnel junction.

The hole of this type of junction is located in the vicinity of 45 degrees of the dark hole arc. The direct bearing structure of this tunnel, which is in the lower part of the arch, is very small. Because this structure is nearly vertical, the vertical load acting on it is small. Then, the load acting on the arch wall becomes the control load.

(2) Compression type light and dark tunnel junction.

The junction of this type of hole is located in the vicinity of 45 degrees of the dark hole arc. Most of the tunnel structure directly comes from the mountain load, and the bearing range of the open hole (mostly bias wall) is very small. The characteristic of this hole is such that the vertical load of the arch ring is dominant, and the horizontal load in the dark hole side has a certain influence.

(3) Combined thrust-compression type light and dark tunnel junction.

The junction of this type of hole is located in the top of the arch. The upper part of the arch mainly sustains the vertical load, and the lower part and side wall sustains the horizontal load. The horizontal and vertical loads are equal, and the thrust and compression work together but interact with each other.

\section{Deformation mechanism of the light and dark tunnel junction}

\subsection{Numerical calculation method}

We used ANSYS to simulate three types of working conditions and to analyze the structure's force characteristics under different load conditions. The structures we studied were mainly associated with the tunnel, including the tunnel's initial support, the open hole's cast-in-situ concrete and retaining wall, and the secondary lining [13-16]. The parameters are analyzed by engineering analogy:

(1) The research object is the tunnel lining structure, and the load is the loose soil pressure. The soil body is $5 \mathrm{~m}$ higher than the vault. The thrust-type light and dark tunnel junction is located in the vicinity of 45 degrees of dark hole arc, and the compression type light and dark tunnel junction is located in the vicinity of 45 degrees of the open hole arc. The combined thrust-compression type light and dark tunnel junction is located in the top of the arch. The plane strain model was used for this analysis.

(2) The calculation parameters of the material are shown in Table 1, and the lateral pressure coefficient of the rock is 0.40 . From the most unfavorable point of view, we consider the rock to be completely loose soil, and we apply the earth pressure load to the single meta-node by the load structure method.

(3) The initial support steel arch, shotcrete, secondary lining and reinforcement are converted, and then we take the comprehensive parameters. The constitutive model is elastic.

(4) According to engineering practice, we take three typical working conditions for analysis: the initial support and temporary support of the upper stage excavation, the full-face excavation without the second lining, and a completed secondary lining. 
Table 1. Parameters of materials for calculation

\begin{tabular}{|c|c|c|c|c|c|}
\hline Material & $\begin{array}{c}\text { Elastic modulus } \\
(\mathrm{GPa})\end{array}$ & $\begin{array}{c}\text { Poisson's } \\
\text { ratio }\end{array}$ & $\begin{array}{c}\text { Density } \\
\left(\mathrm{kg} \cdot \mathrm{m}^{-3}\right)\end{array}$ & $\begin{array}{c}\text { Cohesion } C \\
(\mathrm{kPa})\end{array}$ & $\begin{array}{c}\text { Internal friction } \\
\text { angle } \psi(0)\end{array}$ \\
\hline $\begin{array}{c}\mathrm{C} 25 \\
\text { shotcrete }\end{array}$ & 25 & 0.25 & 2200 & - & - \\
\hline $\begin{array}{c}\mathrm{C} 25 \\
\text { shotcrete }\end{array}$ & 28 & 0.25 & 2300 & - & - \\
\hline $\begin{array}{c}\text { Rockand } \\
\text { soil }\end{array}$ & 3.7 & 0.3 & 1800 & 300 & 37 \\
\hline
\end{tabular}

\subsection{Mechanical characteristics of the half section with temporary support}

The mechanical characteristic of the half section is shown in Figs. 3 to 5, and the specific analysis is as follows:

(1) Deformation characteristics.

Thrust type: when dark hole is in the period of initial support, it appreciably protrudes to the drum $(3.56 \mathrm{~mm})$. During that time, the open hole dome moves up $(1.53 \mathrm{~mm})$ and the top wall moves slightly outward $(0.82 \mathrm{~mm})$. The temporary support of dark hole would protrude due to bending $(2.36 \mathrm{~mm})$. The temporary support of open hole has a tendency toward overturning $(1.37 \mathrm{~mm})$. The deformation in the dark hole is more extensive than in the open one.

Compression type: when dark hole was in the period of initial support, the vault appeared to sink significantly $(20.64 \mathrm{~mm})$. Arch waist squeezes out the hole $(12.95 \mathrm{~mm})$, and the temporary support deforms to both sides $(9.66$ and $9.50 \mathrm{~mm})$. The top of the retaining wall is offset outward $(2.93 \mathrm{~mm})$.

Combined thrust-compression type: The part from the arch foot to the junction of the initial support and temporary support has squeezed out $(1.99 \mathrm{~mm})$. The part from the junction of the initial support and temporary support to the dome subsided slightly $(5.35 \mathrm{~mm})$, and the top of the retaining wall is offset outward $(1.96 \mathrm{~mm})$.

(2) Stress characteristics.

Thrust type: when dark hole is in the period of initial support, the inside of the dark hole is tensed (3.27 MPa) and the outer is compressed $(-5.39 \mathrm{MPa})$. The outer part from the open hole's dome to the junction of open and dark hole is tensed $(1.95 \mathrm{MPa})$, and the inner is under pressure $(-2.65 \mathrm{MPa})$. The part from the open hole to the retaining wall is under a small degree of load. The pressure at the bottom of the retaining wall is substantial $(-3.53 \mathrm{MPa})$. The upper side of junction of the dark hole's temporary support and the retaining wall is tensed (2.94 MPa), and the lower side is compressed $(-3.08 \mathrm{MPa})$. The upper side of the junction between the temporary support and the arch ring of the open tunnel is tensioned, and the lower side is compressed $(-0.68 \mathrm{MPa})$.

Compression type: when the structure is in the initial support, the inner side from the dark hole's arch foot to the arch waist is compressed $(-12.98 \mathrm{MPa})$, whereas the outer side is tensed $(6.50 \mathrm{MPa})$; the outer side from the dark hole's arch waist to the dome is compressed $(-11.26 \mathrm{MPa})$, whereas the inner side is tensed (6.55 MPa); the upper side of the junction between the arch ring and retaining wall is tensed $(2.63 \mathrm{MPa})$, and the lower is compressed $(-4.52 \mathrm{MPa})$. The upper side of the junction between the arch ring and dark hole's temporary support is compressed (-9.82 MPa), and the lower side is tensed (6.51 MPa); the upper side of the junction between the arch ring and open hole's temporary support is compressed $(-13.35 \mathrm{MPa})$, and the lower side is tensed $(0.43 \mathrm{MPa})$.

Combined thrust-compression type: The entire part from dark hole's arch foot to the early and temporary support is compressed (-3.69 $\mathrm{MPa}$ inner hole, $-0.78 \mathrm{MPa}$ outer hole), the outer part from the dome to early and the temporary support is compressed $(-7.84 \mathrm{MPa})$, and the inner part is tensed (4.92 MPa). The outer part from the dome to the retaining walls is tensed (1.06 $\mathrm{MPa})$, and the inner part is compressed $(-2.51 \mathrm{MPa})$. 


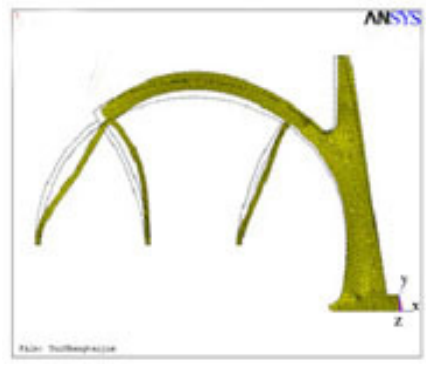

a) Thrust type

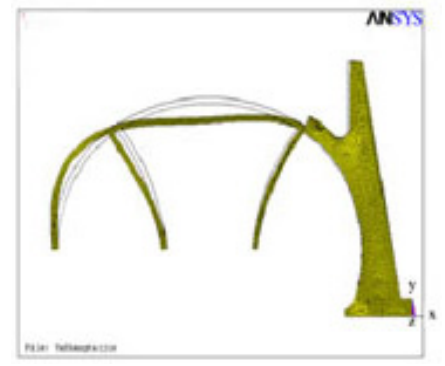

b) Compression type

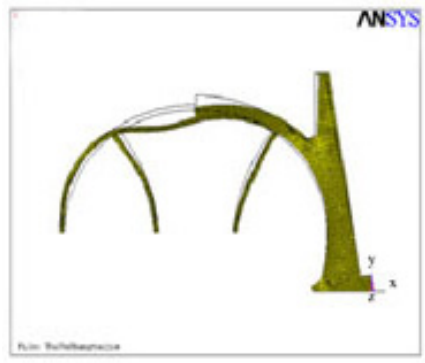

c)Thrust-compression type

Fig. 3. Structural deformation of the primary lining and temporary support of the half section

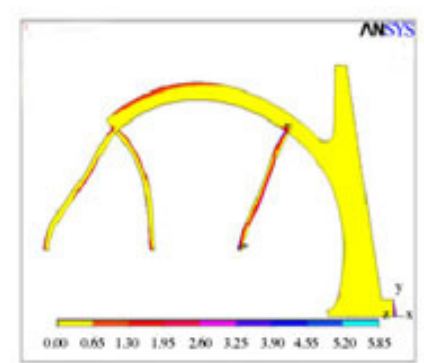

a) Thrust type

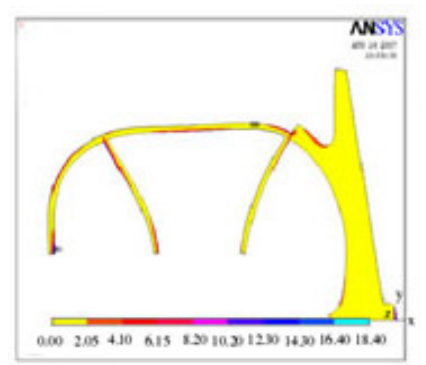

b) Compression type

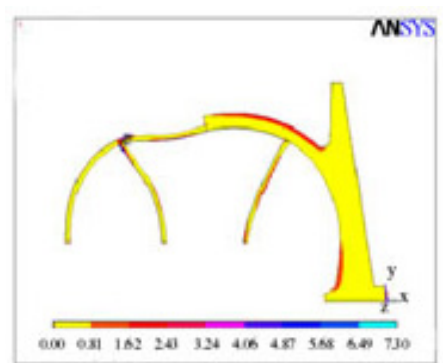

c) Thrust-compression type

Fig. 4. The first principal stress of the primary lining and temporary support of the half section (unit: MPa)

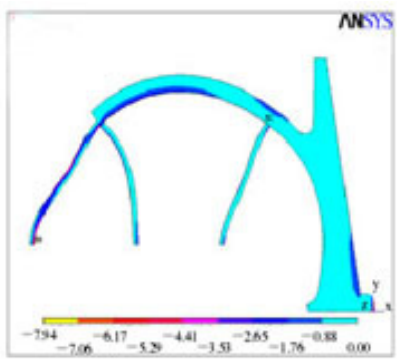

a) Thrust type

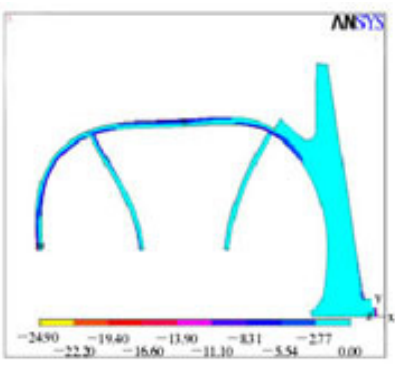

b) Compression type

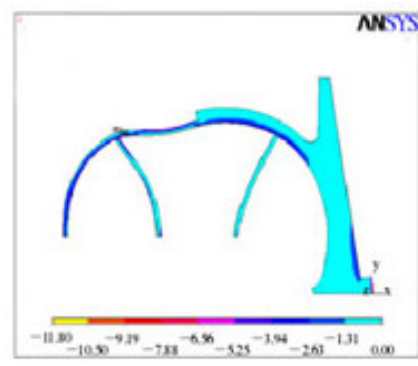

c) Thrust-compression type

Fig. 5. The third principal stress of the primary lining and temporary support of the half section (unit: MPa)

\subsection{Mechanical characteristics of the initial support of the whole section}

The mechanical characteristics of the initial support of whole section are shown in Figs. 6 to 8. The analysis is listed below:

(1) Deformation characteristics.

Thrust type: The dark hole's initial support appreciably protrudes out of the hole $(9.54 \mathrm{~mm})$. The open hole's dome moves up $(6.78 \mathrm{~mm})$, and the top of the retaining wall moves outward $(5.74 \mathrm{~mm})$.

Compression type: When it is in the period of initial support, the dark hole's dome suffers from substantial subsidence $(69.61 \mathrm{~mm})$. The dark hole arch line protrudes out of the hole significantly $(51.58 \mathrm{~mm})$, and the deformation of the upper retaining wall is small $(0.36 \mathrm{~mm})$.

Combined thrust-compression type: The part from the dark hole's arch foot to $2 / 3$ of the arch waist protrudes out of the hole $(19.31 \mathrm{~mm})$. The part from $2 / 3$ of the arch waist to the dome suffers from substantial collapse $(26.94 \mathrm{~mm})$. The collapse of the part from the dome $(11.83 \mathrm{~mm})$ to the retaining wall contact point gradually gets smaller $(2 \mathrm{~mm})$, and the displacement of the upper retaining wall is small $(3.01 \mathrm{~mm})$. 
(2) Stress characteristics.

Thrust type: The inner part of dark hole's initial support is tensed (3.01 MPa), and the outer part is compressed $(-6.37 \mathrm{MPa})$. The outer part of upper open hole is tensed $(2.66 \mathrm{MPa})$, and the inner is compressed (3.74 MPa). The inner part of retaining wall arch line is tensed (2.69 $\mathrm{MPa})$, and the outer is compressed $(-3.17 \mathrm{MPa})$.

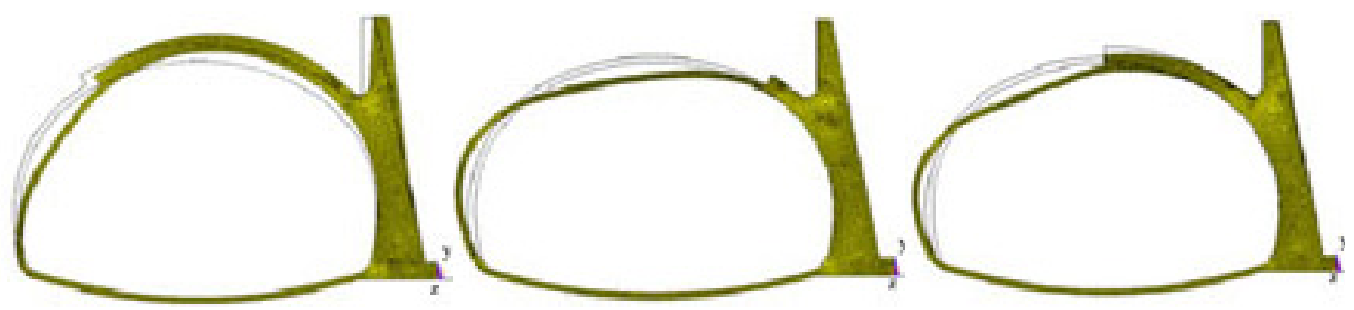

a) Thrust type

b) Compression type

c) Thrust-compression type

Fig. 6. Structural deformation of the primary lining in the whole section

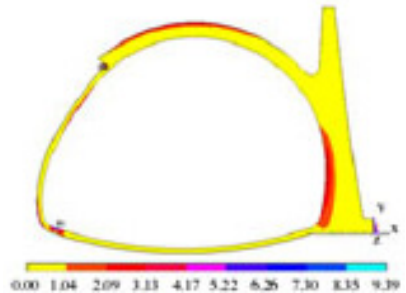

a) Thrust type

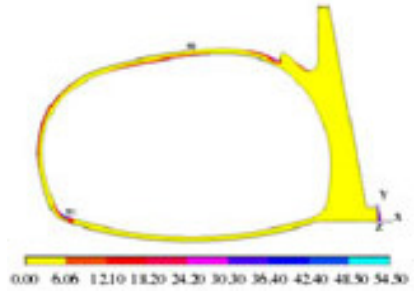

b) Compression type

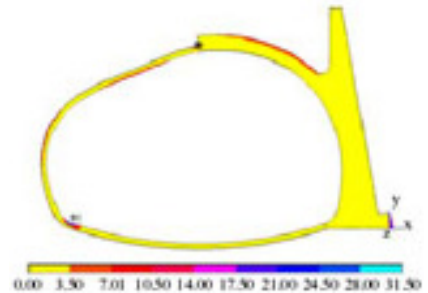

c) Thrust-compression type

Fig. 7. The first principal stress of the primary lining over whole section (unit: MPa)

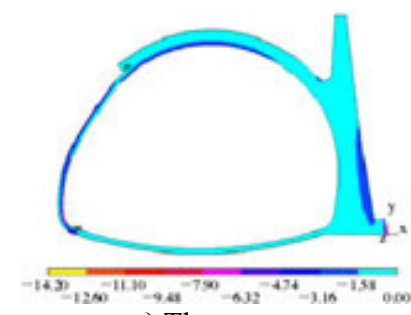

a) Thrust type

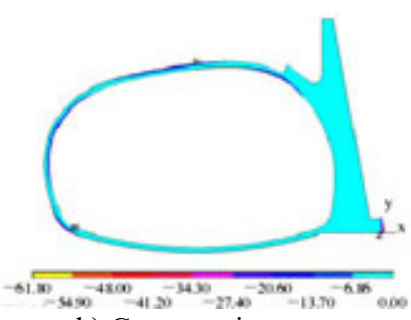

b) Compression type

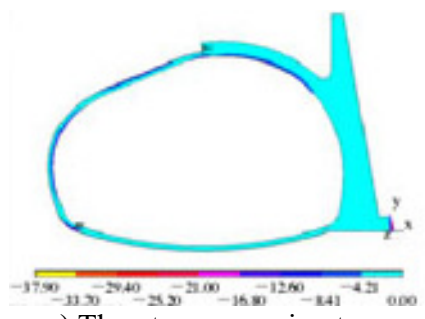

c) Thrust-compression type

Fig. 8. The third principal stress of the primary lining on the whole section (unit: MPa)

Compression type: The inner part from the dark hole's arch foot to the waist's initial support is compressed $(-21.33 \mathrm{MPa})$, and the outer part is tensed $(14.38 \mathrm{MPa})$. The outer part from the arch waist to the junction between open and dark hole is compressed $(-20.48 \mathrm{MPa})$, and the inner is tensed (16.75 MPa). The upper part of the junction between the retaining wall and the arch ring is tensed $(6.66 \mathrm{MPa})$, and the lower is compressed $(-7.68 \mathrm{MPa})$. The entire retaining wall is compressed, and the value is very small.

Combined thrust-compression type: The inner part from dark hole's arch foot to $1 / 3$ of the arch waist is compressed $(-12.69 \mathrm{MPa})$, and the outer is tensed $(6.67 \mathrm{MPa})$. The inner part from $1 / 3$ of the arch waist to the junction between open and dark hole is tensed $(10.17 \mathrm{MPa})$, and the outer is compressed $(-13.48 \mathrm{MPa})$. The inner part from the junction of the retaining wall and the arch to the junction of open and dark hole is compressed $(-4.10 \mathrm{MPa})$, and the outer part is tensed $(2.75 \mathrm{MPa})$. The entire retaining wall is compressed, and the value is very small.

\subsection{Mechanical characteristics of the secondary lining structure}

The mechanical characteristics of the secondary lining structure are shown in Figs. 9 to 11, 
and the concrete analyses are listed below:

(1) Deformation characteristics.

Thrust type: The inner part of the secondary lining structure, which is near the junction of open and dark hole, shows appreciable deformation $(1.29 \mathrm{~mm})$. The vaults move up, but the amplitude is small $(0.95 \mathrm{~mm})$. The upper retaining wall deforms outward $(1.25 \mathrm{~mm})$.

Compression type: The dome of the secondary lining structure in the dark hole suffers from appreciable subsidence $(3.56 \mathrm{~mm})$. The position close to the arch line is distorted outward $(2.37 \mathrm{~mm})$. The top of the retaining wall is deformed inward; however, the amount is small $(0.75 \mathrm{~mm})$.

Combined thrust-compression type: The part from the dark hole's arch foot to $1 / 3$ of the arch waist is distorted outward $(0.80 \mathrm{~mm})$. The part from $1 / 3$ of the arch waist to the dome suffers from appreciable subsidence $(2.49 \mathrm{~mm})$. The sag of the vault $(1.75 \mathrm{~mm})$ toward the retaining wall is gradually reduced $(0.79 \mathrm{~mm})$. The lateral displacement of the upper retaining wall is small $(1.27 \mathrm{~mm})$.

(2) Stress characteristics.

Thrust type: the inner part from the dark hole's arch foot has a maximum stress $(-3.57 \mathrm{MPa})$, and the part from the arch foot to the junction of open and dark hole suffers a gradually weakening pressure. The outside of the junction is compressed $(-0.65 \mathrm{MPa})$, and the inner part is tensed $(0.37 \mathrm{MPa})$. The whole dome is compressed, but the stress outside $(-0.43 \mathrm{MPa})$ is smaller than that of the inner part $(-0.82 \mathrm{MPa})$. The entire retaining wall arch line is compressed $(-0.06 \mathrm{MPa}$ inner part, $-0.43 \mathrm{MPa}$ outside).

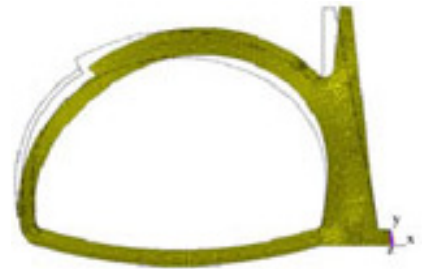

a) Thrust type

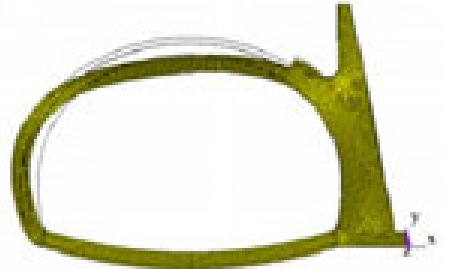

b) Compression type

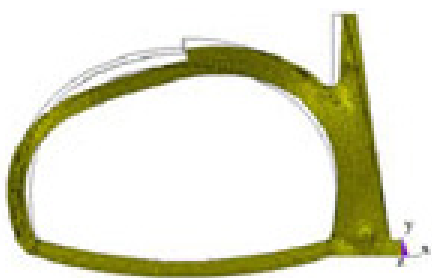

c) Thrust-compression type

Fig. 9. Deformation of the structure after the secondary lining

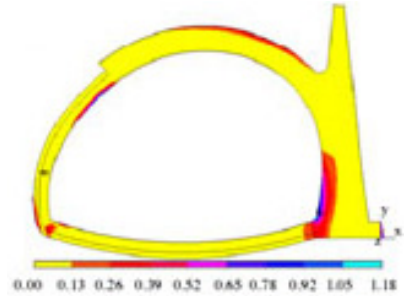

a) Thrust type

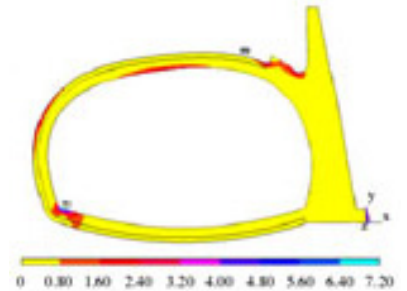

b) Compression type

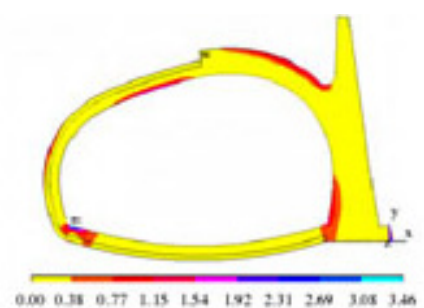

c) Thrust-compression type

Fig. 10. The first principal stress of the structure after the secondary lining (unit: $\mathrm{MPa}$ )

Compression type: The whole secondary lining is compressed, except where the inner part of dome is tensed $(1.67 \mathrm{MPa})$. Both sides of the inner arch waist are compressed (dark hole $-1.47 \mathrm{MPa}$, open hole $-3.08 \mathrm{MPa}$ ), and the whole retaining wall arch line is compressed (inside $-1.48 \mathrm{MPa}$, outside $-0 \mathrm{MPa}$ ).

Combined thrust-compression type: the part from the open hole's arch foot to $1 / 3$ of the arch waist is compressed (inside $-3.24 \mathrm{MPa}$, outside $-0.49 \mathrm{MPa}$ ). The inner part from $1 / 3$ of the arch waist to the junction of the dark and open hole is tensed (1.86 MPa), and the outside is compressed $(-1.56 \mathrm{MPa})$. The part from the junction of the dark and open hole to the junction of the retaining wall and arch is compressed completely $(-1.69 \mathrm{MPa}$ inside, $-0.79 \mathrm{MPa}$ outside). The whole retaining wall arch line is tensed (0.36 $\mathrm{MPa}$ inside, $0.21 \mathrm{MPa}$ outside). 


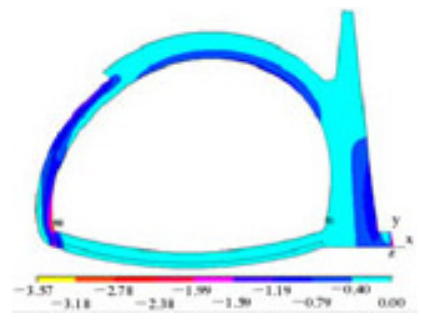

a) Thrust type

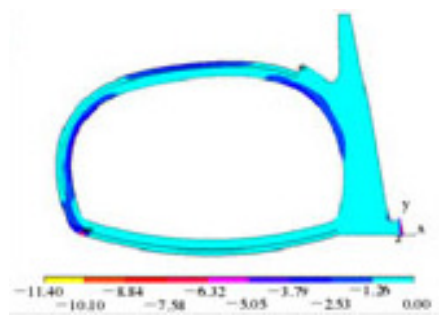

b) Compression type

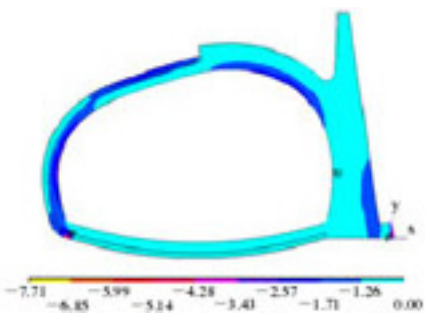

c) Thrust-compression type

Fig. 11. The third principal stress of the structure after the secondary lining (unit: MPa)

\subsection{Statistics for the weak parts of the structure}

Through the numerical analysis, different types of weak parts of the light and dark tunnel junction in different construction stages can be seen in Table 2.

In the actual construction, various conditions may change. Thus, we need to develop a strict monitoring and measuring protocol to ensure the safety of construction, and we should focus on the monitoring of key part of key monitoring projects, as shown in Table 2. We should also take some measures to promptly address unusual circumstances.

Table 2. Weak positions of the structure, and important monitoring items

\begin{tabular}{|c|c|c|c|}
\hline $\begin{array}{l}\text { Construction } \\
\text { stage }\end{array}$ & Thrust tunnel & Compression tunnel & $\begin{array}{l}\text { Combined thrust-compression } \\
\text { tunnel }\end{array}$ \\
\hline $\begin{array}{l}\text { Excavation of } \\
\text { the upper } \\
\text { stage and an } \\
\text { initial } \\
\text { expansion }\end{array}$ & $\begin{array}{l}\text { Initial support of the dark } \\
\text { hole arch: displacement, } \\
\text { pressure, stress dome: } \\
\text { displacement, stress; } \\
\text { middle of the temporary } \\
\text { support: displacement } \\
\text { upper part of the } \\
\text { temporary support: stress } \\
\text { top of retaining wall: } \\
\text { horizontal displacement; } \\
\text { bottom of the wall } \\
\text { outside: stress }\end{array}$ & $\begin{array}{l}\text { Dome: displacement, } \\
\text { pressure, stress dark } \\
\text { hole arch: } \\
\text { displacement, pressure } \\
\text { temporary support of } \\
\text { the dark hole: } \\
\text { displacement top of } \\
\text { retaining wall: } \\
\text { horizontal } \\
\text { displacement junction } \\
\text { of dark and open hole: } \\
\text { stress }\end{array}$ & $\begin{array}{l}\text { Arch ring on both sides of } \\
\text { temporary support: } \\
\text { displacement, stress upper } \\
\text { part of temporary support on } \\
\text { dark hole: displacement, stress } \\
\text { middle part of temporary } \\
\text { support on open hole: } \\
\text { displacement, stress part from } \\
\text { the dark hole arch to the } \\
\text { temporary support joints: } \\
\text { pressure lower part of } \\
\text { retaining wall: stress top of } \\
\text { retaining wall: horizontal } \\
\text { displacement }\end{array}$ \\
\hline $\begin{array}{l}\text { Full-face } \\
\text { excavation } \\
\text { and an initial } \\
\text { support }\end{array}$ & $\begin{array}{l}\text { Initial support of the dark } \\
\text { hole arch: displacement, } \\
\text { pressure, stress dome: } \\
\text { displacement, stress top } \\
\text { of retaining wall: } \\
\text { horizontal displacement; } \\
\text { height of retaining wall } \\
\text { arching line: stress }\end{array}$ & $\begin{array}{c}\text { Dome: displacement, } \\
\text { pressure, stress dark } \\
\text { hole arch: } \\
\text { displacement, pressure } \\
\text { junction of dark and } \\
\text { open hole: stress } \\
\text { deformation of slope } \\
\text { near the dark hole: } \\
\text { displacement }\end{array}$ & $\begin{array}{l}\text { Temporary support on dark } \\
\text { hole: displacement, stress } \\
\text { deformation of slope near the } \\
\text { dark hole: displacement }\end{array}$ \\
\hline $\begin{array}{l}\text { Secondary } \\
\text { lining }\end{array}$ & $\begin{array}{l}\text { Junction of dark and open } \\
\text { hole: stress arch feet: } \\
\text { stress top of retaining } \\
\text { wall: horizontal } \\
\text { displacement }\end{array}$ & $\begin{array}{l}\text { Dome: displacement, } \\
\text { pressure, stress dark } \\
\text { hole arch: stress dark } \\
\text { hole arch feet: stress }\end{array}$ & $\begin{array}{l}\text { Part form arch feet to arch } \\
\text { waist in dark hole: stress, } \\
\text { pressure shoulder in open } \\
\text { hole: stress open hole arch } \\
\text { line: stress }\end{array}$ \\
\hline
\end{tabular}

\section{In-site monitoring}

Based on the theoretical analysis above, we carried out a special monitoring program in four three-lane light and dark tunnel junctions on the Huangta (Tao) highway. Through targeted 
monitoring, we identified the abnormal situation of the tunnel in time, and it was treated the first time, thus ensuring the safety of the tunnel. The following is an illustration of the right exit of the Changwuling Tunnel (Taling end).

\subsection{Monitoring project}

(1) We looped the seven points in the arch. These measuring points are mainly arranged in the dark hole, which could monitor the dark hole's sinking situation.

(2) Strain gauges are arranged in the inner part of the retaining wall and the open hole, which could monitor the situation of the fixture, I-steel and concrete strain.

(3) Strain gauges are arranged in the inner part of the dark hole, which could monitor the situation of the fixture, I-steel and concrete strain.

(4) The pressure box is arranged in the dark hole, which could monitor the pressure of the surrounding rock and initial support, primary support and secondary lining.

(5) A measuring point is arranged at the top of the retaining wall, which monitors the horizontal displacement of the retaining wall.

(6) Finally, the cracks should be observed everywhere.

\subsection{Monitoring results}

We found that the deformation of the structure, which is inside the dark hole and above the hole's step, will expand continually. The results are as follows:

(1) Subsidence of the protective arch in the dark hole will extend continually (in Fig. 12).

The maximum settlement occurred in measuring points 5 through 7 , in which the angle between the dark hole side and the horizontal line was 45 degrees to 60 degrees. The maximum accumulated settlement reached $56.4 \mathrm{~mm}$.

(2) The top of the retaining wall offset outward up to $38.6 \mathrm{~mm}$. The crack between the retaining wall's ear wall and the backfill in the open hole reached $31 \mathrm{~mm}$ (Fig. 13(a)).

(3) Some longitudinal cracks have appeared in the arch waist and dome (junction of the dark and open hole) in the dark hole. The widest has reached $5 \mathrm{~mm}$, with longitudinal lengths from 1 to $5 \mathrm{~m}$.

(4) Some cracks of approximately $20 \mathrm{~mm}$ have appeared in the edge of the junction of the retaining wall and open hole's arch (Fig. 13(b)).

(5) The part from the outside of the retaining wall to the arch line has a longitudinal crack due to comprehensive fracture.

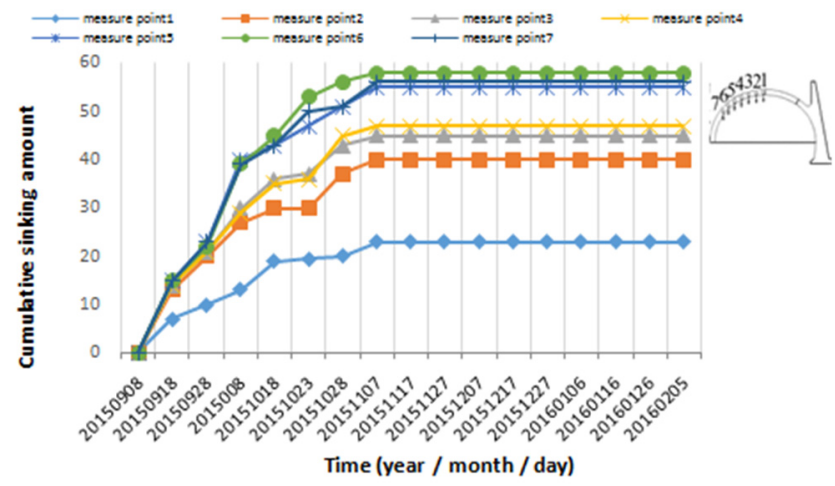

Fig. 12. Settlement development of the protective at the exit of right line of the Changwuling tunnel arch

\subsection{Analysis and treatment}

During the monitoring process, with analysis of the monitoring data, we find that this tunnel's 
deformation and mechanical characteristics are similar to those of the combined thrust-compression light and dark tunnel junction. We have taken some measures according to the monitoring results, as follows:

(1) In early October 2006, subsidence of the protective arch in dark hole has extended continually. At the first instance, we posed a warning and reinforced recommendations, but nothing was done.

(2) Then, in mid-October, subsidence of the protective arch in the dark hole extended continually. A rapid development occurred on October 23rd, and structural damage appeared. Then, we quickly issued an emergency suggestion. We suggested that we should take the balance of pressure and increase the vertical bearing capacity to reinforce the structure: backfill the outside retaining wall; backfill the top of the open hole; grout the inner part of the dark hole's arch waist by small duct; and build temporary support inside the hole. Because the speed of the implementation was not fast enough, a small-scale slump occurred on the slope of dark hole, but the deformation was finally controlled.

(3) The deformation and stress of the combined thrust-compression tunnel will improve after full-face excavation. According to these characteristics, when the deformation of the upper half section is controlled, we can speed up the excavation of the lower step and close it into a ring.

\subsection{In-suit monitoring results}

According to Changwuling tunnel right line's exit and the other three light and dark tunnel junction field tests (omitted in this article due to limited space), we draw the conclusion that the actual displacement and mechanical characteristics of the structure are consistent with the theoretical analysis, and the actual displacement value is even larger than the calculated value. This is very common in the tunnel construction. On the one hand, there are some differences between the actual construction and the theoretical model; for example, some settlement may occur in the arch foot. On the other hand, the assumed condition of small deformation is not satisfied when the structure fails. The treatment scheme based on the characteristics of the corresponding structure can effectively control the tunnel's abnormal deformation and can prevent disasters.

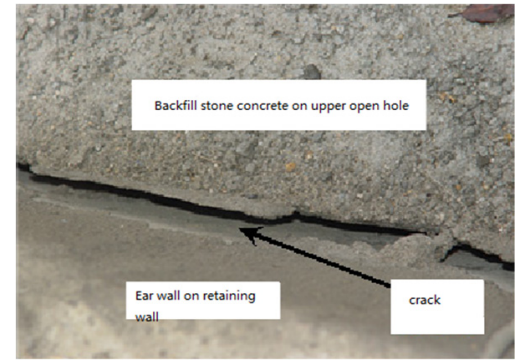

a) Retaining wall and roof backfill stripping

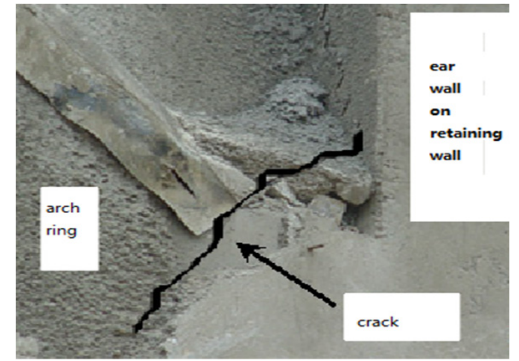

b) Cracks at the junction of the retaining wall and arch

Fig. 13. Some cracks at the exit of the right line of the Changwuling Tunnel

Lv Jianbing is in charge of overall planning. Wu Yimin and Yin Yingmei are responsible for technical guidance. Wang Fei and Zou Zhengming provided monitoring data. Li Xulong is responsible for numerical simulation.

\section{Conclusions}

1) Light and dark tunnel junctions have a complex structure and changeable loads. According to their horizontal load and vertical load's proportion, we divided these junctions into three types: compression type, thrust type, and combined thrust-compression type. With these categories, we can successfully carry out targeted studies that could guide the construction and monitoring. 
2) With the method of the numerical simulation, we analyze the displacement and stress distributions of the three types of light and dark tunnel junctions. Then, we have mastered the deformation and mechanical characteristics of various types of structures. Furthermore, no matter what the construction stage, we can determine the weak parts of the various structures. Then, we can propose targeted monitoring projects.

3) Actual field test results show that the actual displacement and stress distribution of the structure is consistent with the theoretical analysis results. Then, according to the corresponding structure's characteristics, some related engineering measures can be taken to control the abnormal deformation of structures very effectively.

4) Theoretical analysis has simplified the actual load. In practice, it is necessary to determine the load according to the actual terrain, geological, and surrounding rock conditions. Then, we divide the structure type by its actual bearer.

\section{Acknowledgements}

Authors sincerely thank Professor Wu Yimin of Central South University, Wang Fei of Anhui Institute of Transportation Planning and Design, and Zou Zhengming of Anhui Transportation Investment Group for their strong support and guidance in the process of writing the paper. We would like to express our heartfelt thanks.

\section{References}

[1] Koneshwaran S., Thambiratnam D. P., Gallage C. Blast response and failure analysis of a segmented buried tunnel. Structural Engineering International, Vol. 25, Issue 4, 2015, p. 419-431.

[2] Koneshwaran S., Thambiratnam D. P., Gallage C. Performance of buried tunnels subjected to surface blast incorporating fluid structure interaction. Journal of Performance of Constructed Facilities, Vol. 29, Issue 3, 2015, https://doi.org/10.1061/(ASCE)CF.1943-5509.0000585.

[3] Alhaddad M., Wilcock M., Gue C. Y., Bevan H., Stent S., Elshafie M. Z. E. B., et al. Multi suite monitoring of an existing cast iron tunnel subjected to tunnelling induced ground movements. Geo-Shanghai International Conference, 2014.

[4] Jeong H. G., Seo Y. S. Slope stability analysis and landslide hazard assessment in tunnel portal area. Journal of Korean Tunnelling and Underground Space Association, Vol. 15, Issue 4, 2013, p. 387-400.

[5] Wang K., Kang H. G., Wang H. T. Recovery execution in landslide at the portal of highway tunnel. Advanced Materials Research, Vol. 250, 2011, p. 1823-1826.

[6] Kostić S., Vasović N., Sunarić D. Slope stability analysis based on experimental design. International Journal of Geomechanics, Vol. 16, Issue 5, 2016, https://doi.org/10.1061/(ASCE)GM.19435622.0000551 .

[7] Rhayma N., Talon A., Breul P., Goirand P. Mechanical investigation of tunnels: risk analysis and notation system. Structure and Infrastructure Engineering, Vol. 12, Issue 3, 2016, p. 381-393.

[8] Fahimifar A., Zareifard M. R. A theoretical solution for analysis of tunnels below groundwater considering the hydraulic-mechanical coupling. Tunnelling and Underground Space Technology, Vol. 24, Issue 6, 2009, p. 634-646.

[9] Ariznavarreta-Fernández F., González-Palacio C., Menéndez-Díaz A., Ordoñez C. Measurement system with angular encoders for continuous monitoring of tunnel convergence. Tunnelling and Underground Space Technology, Vol. 56, 2016, p. 176-185.

[10] Jiang S. P., Li J. J. 3D simulation and analysis of highway tunnels by use of advanced entrance construction method. Chinese Journal of Geotechnical Engineering-Chinese Edition, Vol. 29, Issue 4, 2007, p. 484.

[11] Castellanos B. A., Brandon T. L., Vandenberge D. R. Use of fully softened shear strength in slope stability analysis. Landslides, Vol. 13, Issue 4, 2016, p. 697-709.

[12] Monthly Report of Tunnels Monitoring for Huangshan-Taling and Xiaohe-Taolin Highways. Chang'an University, China, 2006.

[13] Zhang Yanxin, Cai Meifeng, Qiao Lan Study on mechanical response to excavation and support of expressway tunnel. Chinese Journal of Rock Mechanics and Engineering, Vol. 25, Issue 6, 2006, p. $1284-1289$. 
[14] Wang Yixian, Guo Panpan, Dai Feng, Li Xian, Zhao Yanlin, Liu Yan Behavior and modeling of fiber-reinforced clay under triaxial compression by combining the superposition method with the energy-based homogenization technique. International Journal of Geomechanics, Vol. 18, Issue 12, 2018, p. 04018172.

[15] Wu Zhenzhi, Fu Zhifeng, Wang Jing Study of support mechanism and effect of shed-pipe grouting technology for tunneling construction shallow-buried soft stratum. Chinese Journal of Rock Mechanics and Engineering, Vol. 24, Issue 6, 2005, p. 1025-1029.

[16] Wang Yixian, Guo Panpan, Ren Weixin, Yuan Bingxiang, Yuan Haiping, Zhao Yanlin, Shan Shengbiao, Cao Ping Laboratory investigation on strength characteristics of expansive soil treated with jute fiber reinforcement. International Journal of Geomechanics, Vol. 17, Issue 11, 2017, p. 04017101.

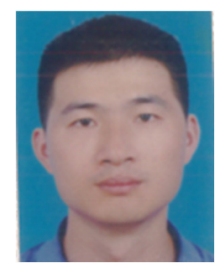

Jianbing Lv holds a Doctorate from the School of Civil and Transportation Engineering, Central South University. He is now a Professor at the School of Civil and Transportation Engineering, Guangdong University of Technology. At present, it mainly studies the direction of rock, soil and road.

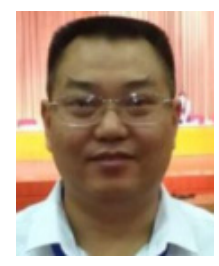

Yimin Wu is a Professor at Zhongnan University. At present, he mainly studies highway and waterway transportation, mining engineering, geology.

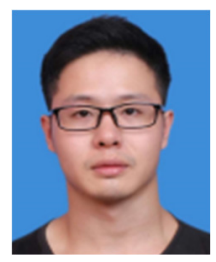

Xulong Li is a Master of Civil and Transportation Engineering College of Guangdong University of Technology. The research direction is geotechnical engineering.

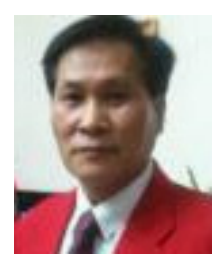

Fei Wang is currently working in Anhui Institute of Transportation Planning and Design. His research direction is bridge and tunnel engineering.

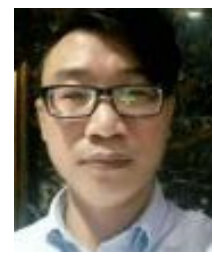

Zou Zhengming is currently working for Anhui Transportation Investment Group.

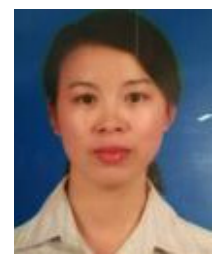

Yingmei Yin graduated from South China University of Technology with a doctorate. At present, he is an Associate Professor of Civil and Transportation Engineering College of Guangdong University of Technology. 